\title{
Prize winners at the 49th Annual Meeting of the European Society of Paediatric Radiology, Athens, Greece 2012
}

(C) Springer-Verlag 2012

\section{The Jacques Lefebvre prize}

Jose Vazquez, Spain. External manual reduction with US assistance: a new procedure for paediatric idiopathic ileocolic intussusception

\section{The young investigator award}

Lene Bjerke Laborie, Norway. Associations between femoroacetabular impingement and hip dysplasia as demonstrated radiographically. Preliminary results.

\section{The poster award}

Owen Arthurs, UK. Diffusion-weighted MRI of the fetal brain in intrauterine growth restriction.

\section{The President's prize}

Polis Xenophontos, Greece. Detection of primary sclerosing cholangitis-type lesions in children with inflammatory bowel disease at MRCP: relative risk measurement analysis. 